\title{
Promoting Bandung Small and Medium Enterprises (SMEs) Development through E-Commerce
}

\author{
Prayoga ${ }^{1}$, Sylvia Octa Putri ${ }^{2}$ \\ \{ prayoga@email.unikom.ac.id $^{1}$, sylvia.octa.putri@email.unikom.ac.id ${ }^{2}$ \}
}

Department of Information System, Universitas Komputer Indonesia, Indonesia ${ }^{1}$

Department of International Relations, Universitas Komputer Indonesia, Indonesia ${ }^{2}$

\begin{abstract}
The purpose of this study is to identify the development of E-Commerce technology in Bandung for Small and Medium Enterprises (SMEs) and the benefits of E-Commerce applications in SMEs. The method used in this research is descriptive analysis method. The results of this study are Little Bandung is one of the support programs of the city government of Bandung to strengthen the competitiveness of Bandung Products, to encourage the participation of SMEs in the global value chain so that they can be active in international business and contribute to the country's economy. These programs are made in the form of promoting Bandung products to domestic and international markets. However, the use of ICT is only limited to the promotion and display of information on the products of some SMEs in Bandung, not directly selling through the internet. Bandung Cooperative and SME Office also need to continue to encourage existing SMEs to be able to use the facilities available to the market and display their products.
\end{abstract}

Keywords : SMEs, ICT, Promotion, International Markets, E-Commerce

\section{Introduction}

Fensel, et al. the rapid development of information and communication technology, known as Information and Communication Technology (ICT) and the internet has penetrated various fields of life, including business and commerce [1]. Likewise, with Jinling et al. the internet and ICT, the process of marketing and sales can be done at any time without being bound by space and time [2]. According to Kim et al. trust and customer satisfaction are the most important part of building a good business relationship in e-commerce business to consumers [3]. Research conducted by Wilson, et al found five factors found to influence E-Commerce, namely management support, the benefits of understanding management systems, the presence of IT skills, the availability of SME consultations and priorities [4]. Compared to research conducted by Solaymani, et al they examined important factors that have an impact on the tendency of SMEs to use electronic commerce [5]. Ghobakhloo et al. examine factors in the framework of the Technology-Organization-Environment (TOE) that influence the decision to adopt E- 
Commerce and the rate of adoption of E-Commerce, as well as the adoption and non-adoption of E-Commerce applications [6]. Lawrence and Tar show problems that hinder the adoption of E-Commerce in developing countries [7].

Research conducted by Scupola explains that the factors that influence the adoption \& application of Business-to-Business E-Commerce in SMEs and provide some interesting perspectives from Danish and Australian SMEs [8]. Kapurubandara and Lawson stated that ECommerce offers practical solutions for organizations to deal with a changing environment [9].

Fithian et al. reviewed proposed e-readiness assessment models for countries at the macro scale and then identified important factors for the assessment of SME e-readiness [10]. The purpose of this study is to identify the development of e-commerce technology in the world of online business and the benefits of the application of e-commerce in the online business. According to Eddy Soeryanto Soegoto shopper is a person who can be categorized as an entrepreneur or entrepreneur (modern economic theory). If the business is stagnant or not developing, then the business is called Entrepreneur while growing, developing, and advancing, the entrepreneur is called Entrepreneurship [11]. The purpose of this study is to explore the technology of E-Commerce in Small and Medium Enterprises (SMEs), and the benefits of ECommerce applications in SMEs. The method used in this research is descriptive analysis method.

\section{Material and Methods}

This study used a descriptive analysis method to determine variables related to E-Commerce and SMEs and previous research related to E-Commerce development and online marketing. So that it could analyze how much influence E-Commerce technology in SMEs.

\section{Results and Discussion}

\section{A. Basic Concepts E-Commerce}

E-Commerce is part of E-Business, where E-Business coverage is broader. The definition of ECommerce globally is all forms of trade transactions for goods or services carried out electronically. According to Adriana, E-Commerce is a way to shop or trade online using internet facilities where there are websites that provide services [11].

Meanwhile, according to Karmawan E-commerce is a type of electronic business mechanism that focuses on individual-based business transactions by using the internet as a medium for exchanging goods or services both Business to Business (B2B) and Business to Consumer (B2C). With the E-Commerce application, the relationship between the company and other partners can be made faster, more intensive, and cheaper than the application of the management principles in Door to Door, and One-To-One Relationship [12].

According to Teo et al., one of the media used in e-Commerce is the internet. This media development is the most rapid compared to other media in supporting e-Commerce. There are two supporting factors that cause the internet to grow faster in e-Commerce, namely (1) the internet has a very wide range, cheap, fast, and easily accessible to the public; (2) the internet uses electronic data as a medium for delivering messages/data so that information can be sent and received easily and concisely, both in the form of analog and digital electronic data [13].

\section{B. E-Commerce as a SMEs Development}

To continuously improve the competitiveness of SMEs and gain export opportunities \& other business opportunities. One strategy that can be used is to utilize Information and Communication Technology (ICT) development. The most widely used ICT is E-Commerce 
Little Bandung is one of the support programs of the city government of Bandung to strengthen the competitiveness of Bandung Products, to encourage the participation of SMEs in the global value chain so that they can be active in international business and contribute to the country's economy. These programs are made in the form of promoting Bandung products to domestic and international markets (Fig. 1).

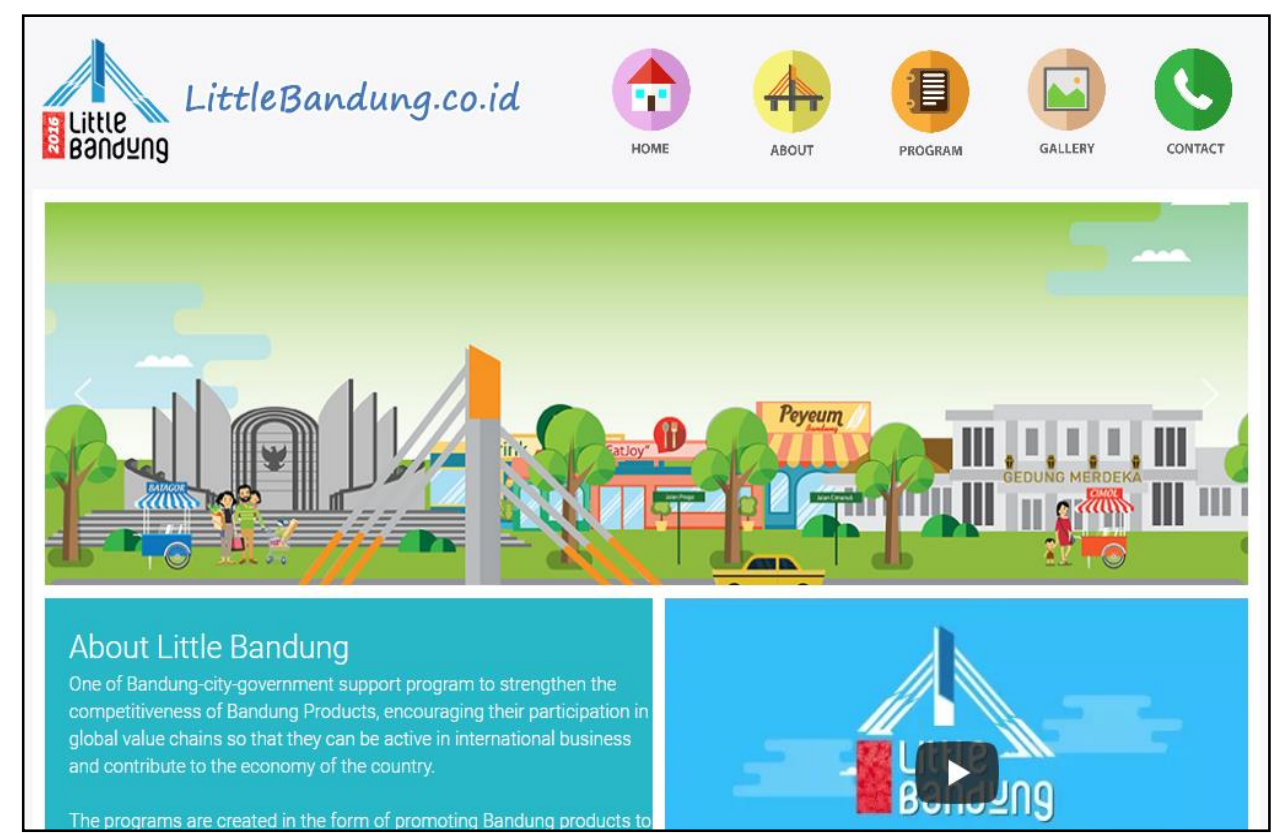

Fig 1. Main menu.

In the main menu view, there are several parts, such as menus and submenus. The seller can register the product to be promoted. There are several products offered, ranging from Fashion, Craft, Culinary, etc. So that buyers can easily find products (Fig. 2). 


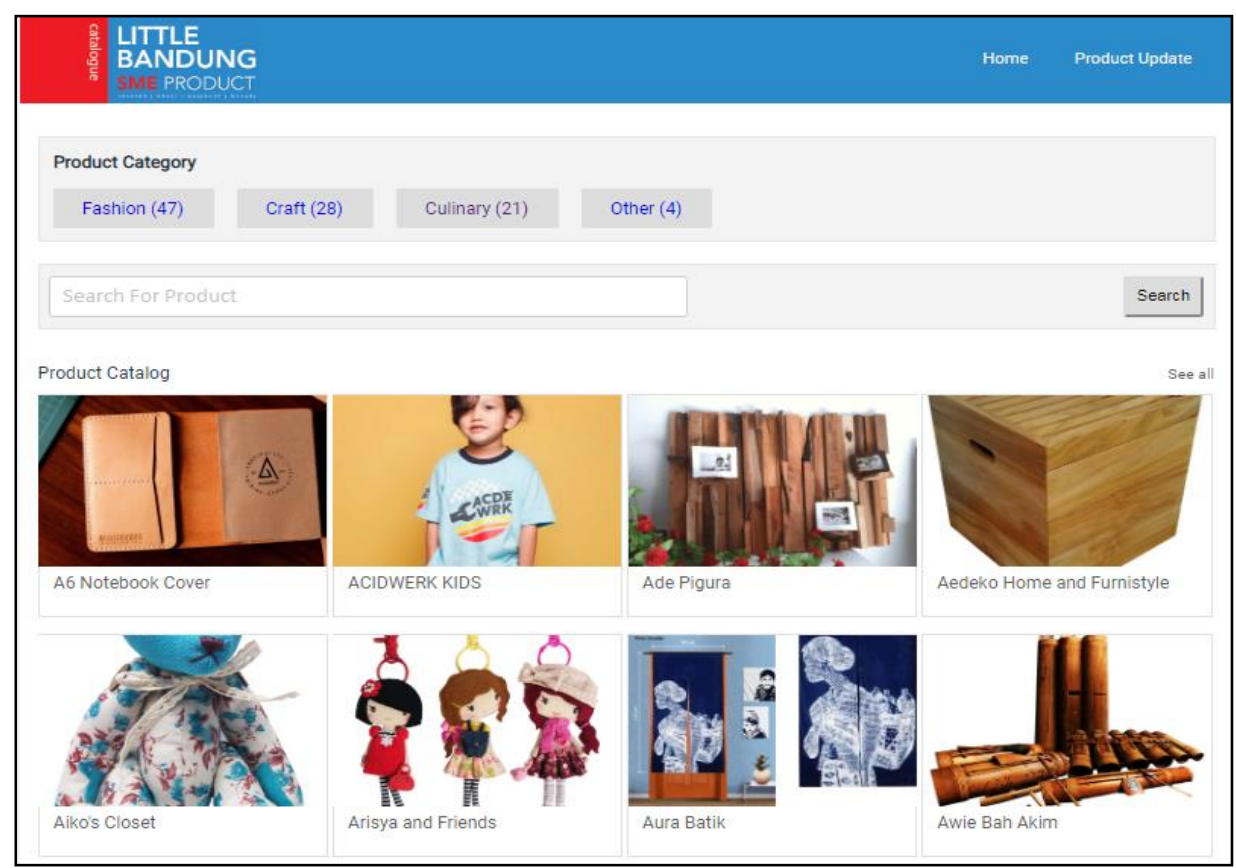

Fig 2. Product Menu.

In the product display, the Buyer can choose or search for the desired item. Products in Little Bandung are original products from Bandung, the products displayed include full addresses, e-mails, telephone numbers, social media, and product names so that the buyer can contact the seller to find out the price of the item (Fig. 3).

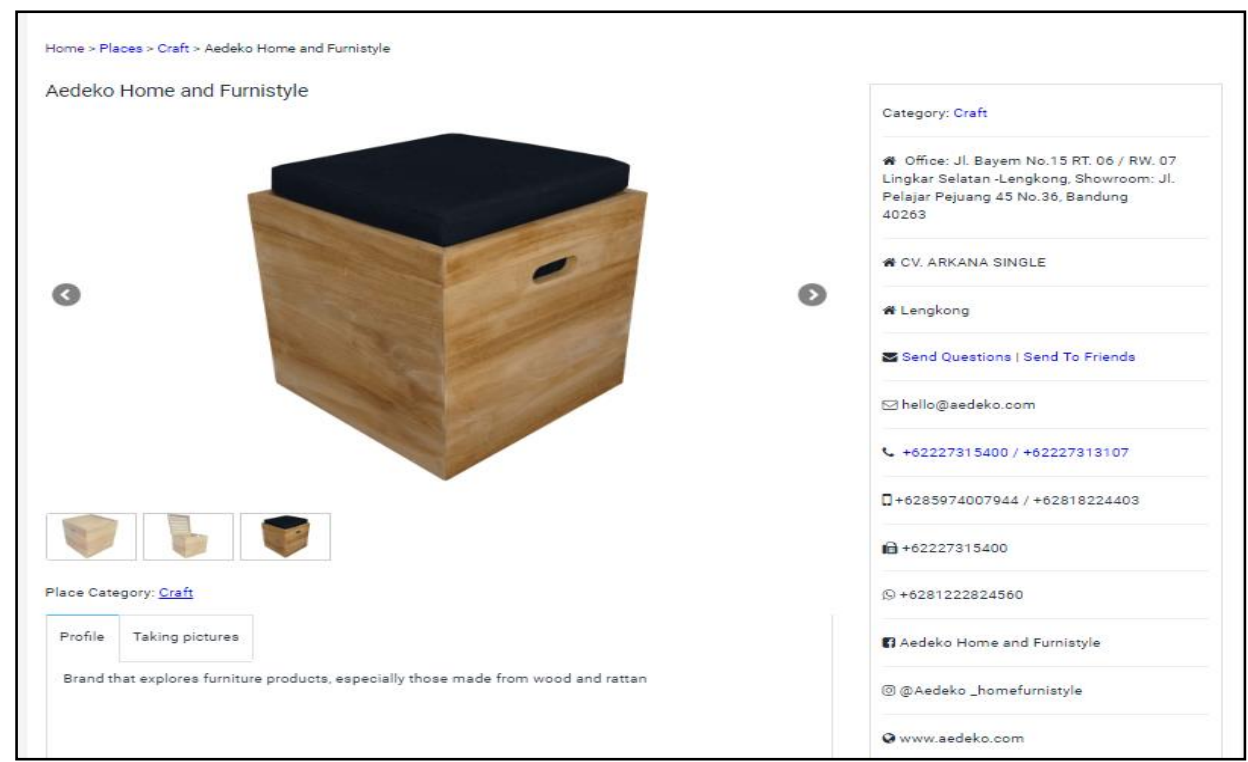

Fig 3. Product Information. 
After the Buyer selects the desired item, the Buyer can send the seller an inquiry regarding the item to be purchased. There, the Buyer can include an Email address and telephone number, to make it easier for the Seller to contact the Buyer regarding his order (Fig. 4).

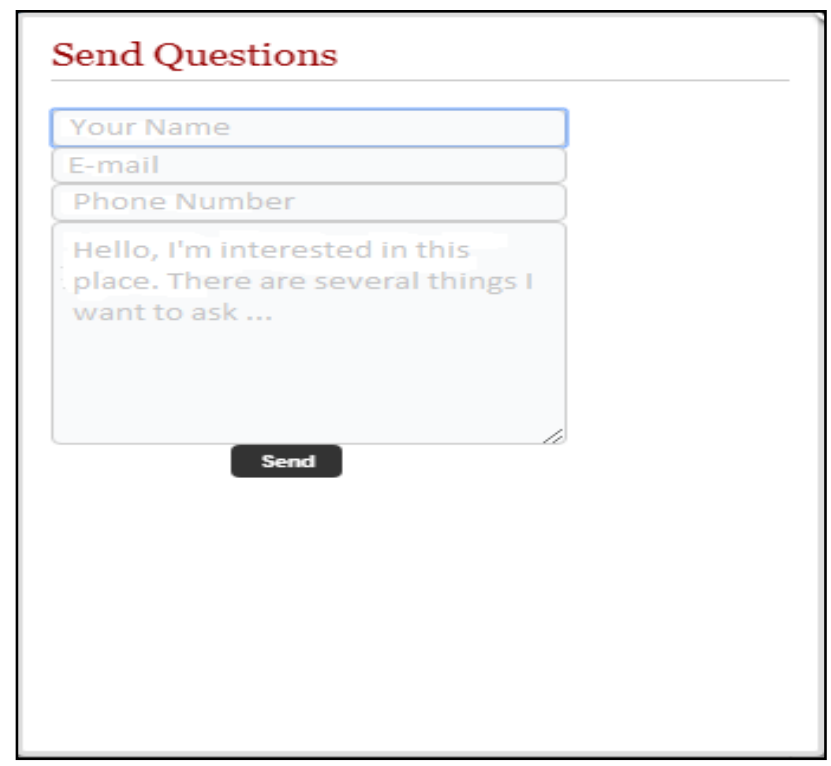

Fig 4. Send Questions.

In addition to the Send Questions facility, here also provides Send to Friends. At this facility, Buyers can distribute Products to their friends by entering your friend's name and email address. So that your friends can visit this site, if there is something interesting (Fig. 5).

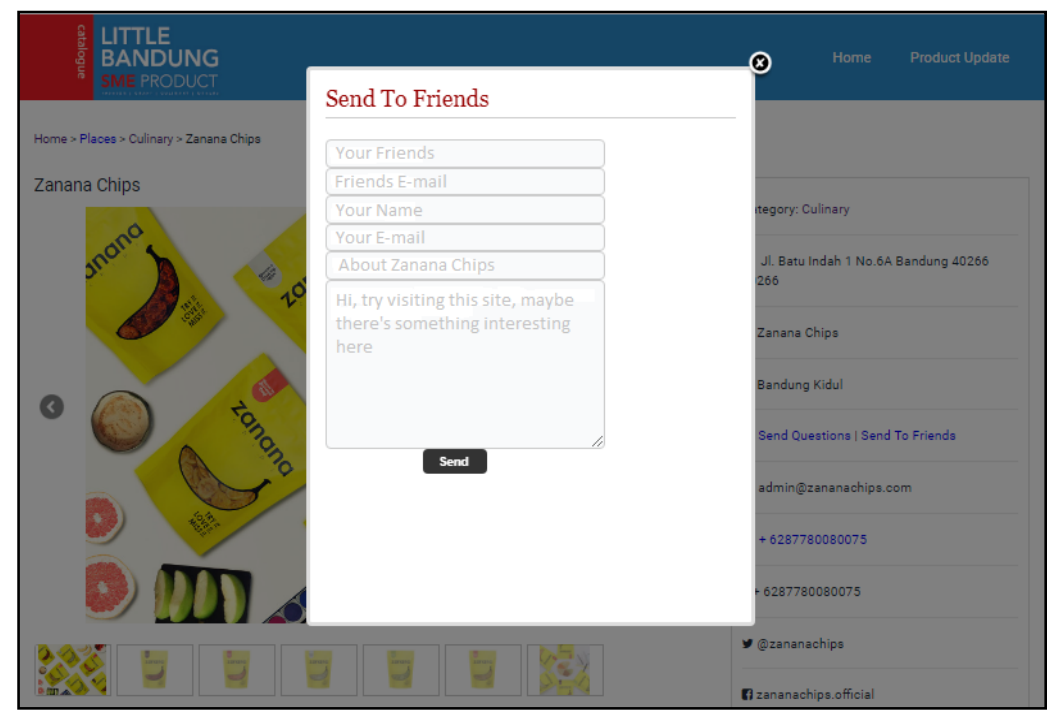

Fig 5. Send Friends. 
However, the use of ICT is only limited to the promotion and display of information on the products of some SMEs in Bandung, not directly selling through the internet, such as sales on Alibaba.com. By using E-Commerce that can be used for online marketing and sales will certainly increase sales volume and ultimately will increase business revenue and eventually will develop Small and Medium Enterprise.

\section{Conclusion}

To improve the competitiveness of SMEs to get export opportunities and other business opportunities can be done by utilizing the development of Information and Communication Technology (ICT), especially E-Commerce. Not only use the internet as a tool to promote or look for business opportunities, but it also must be balanced with good administrative management through the use of appropriate software. Website development and E-Commerce need to be done as a means to promote and market business products so that they will increase sales volume and increase revenue. This revenue increase will eventually develop Small and Medium Enterprises. On the other hand, the Bandung Cooperative and SME Office also need to continue to encourage existing SMEs to be able to use the facilities available to the market and display their products

\section{References}

[1] Fensel, D., Ding, Y., Omelayenko, B., Schulten, E., Botquin, G., Brown, M., \& Flett, A. :Product data integration in B2B e-commerce. IEEE Intelligent Systems, 16(4), 54-59. (2001).

[2] Jinling, C., Tong, S., Chuncan, L., \& Tao, S. :Modeling e-commerce website quality with quality function deployment. In e-Business Engineering, 2009. ICEBE'09. IEEE International Conference on (pp. 417-422). IEEE. October (2009).

[3] Kim, D. J., Ferrin, D. L., \& Rao, H. R. :Trust and satisfaction, two stepping stones for successful e-commerce relationships: A longitudinal exploration. Information systems research, 20(2), 237 257. (2009).

[4] Wilson, H., Daniel, E., \& Davies, I. A. :The diffusion of e-commerce in UK SMEs. Journal of marketing management, 24(5-6), 489-516. (2008).

[5] Solaymani, S., Sohaili, K., \& Yazdinejad, E. A. :Adoption and use of e-commerce in SMEs. Electronic Commerce Research, 12(3), 249-263. (2012).

[6] Ghobakhloo, M., Arias-Aranda, D., \& Benitez-Amado, J.: Adoption of e-commerce applications in SMEs. Industrial Management \& Data Systems, 111(8), 1238-1269. (2011).

[7] Lawrence, J. E., \& Tar, U. A. :Barriers to e-commerce in developing countries. Information, society and justice journal, 3(1), 23-35. (2010).

[8] Scupola, A. SMEs e-commerce adoption: perspectives from Denmark and Australia. Journal of Enterprise Information Management, 22(1/2), 152-166. (2009).

[9] Kapurubandara, M., \& Lawson, R. :Availability of e-commerce support for SMEs in developing countries. ICTer, 1(1). (2008).

[10] Fathian, M., Akhavan, P., \& Hoorali, M. :E-readiness assessment of non-profit ICT SMEs in a developing country: The case of Iran. Technovation, 28(9), 578-590. (2008).

[11] Soegoto, E. S.: Entrepreneurship Menjadi Pebisnis Ulung Edisi Revisi. Elex Media Komputindo. (2014).

[12] Karmawan, I. G. M., Sundjaja, A. M., \& Luhukay, D. :Analisis dan Perancangan E-commerce PD. Garuda Jaya. In Seminar Nasional Aplikasi Teknologi Informasi (SNATI). June (2010).

[13] Teo, T. S., Ranganathan, C., \& Dhaliwal, J.: Key dimensions of inhibitors for the deployment of web-based business-to-business electronic commerce. IEEE Transactions on Engineering Management, 53(3), 395-41 (2006). 